\title{
Hydroxyurea for sickle cell disease in children and for prevention of cerebrovascular events: the Belgian experience
}

Béatrice Gulbis, David Haberman, Dominique Dufour, Catherine Christophe, Christiane Vermylen, Faustin Kagambega, Francis Corazza, Christine Devalck, Marie-Françoise Dresse, Kathleen Hunninck, Axel Klein, Phu Quoc Le, Michèle Loop, Philip Maes, Pierre Philippet, Eric Sariban, Chris Van Geet, and Alina Ferster

Hydroxyurea $(\mathrm{HU})$ is considered to be the most successful drug therapy for severe sickle cell disease (SCD). Nevertheless, questions remain regarding its benefits in very young children and its role in the prevention of cerebrovascular events. There were 127 SCD patients treated with no attempt to reach maximal tolerated doses who entered the Belgian Registry: 109 for standard criteria and 18 who were at risk of stroke only. During 426 patientyears of follow-up for patients with stan- dard criteria, 3.3 acute chest syndromes, 1.3 cerebrovascular events, and 1.1 osteonecrosis per 100 patient-years were observed. A subgroup of 32 patients followed for 6 years experienced significant benefit over this period. In each subgroup of children (younger than 2 years, 2-5, 6-9, and 10-19 years) followed for 2 years, clinical and biologic changes were similar, except for children younger than 2 years who had no total hemoglobin increase and remained at risk of severe anemia. In 72 patients evaluated by transcranial Doppler studies (TCD), 34 patients were at risk of primary stroke and only 1 had a cerebrovascular event after a follow-up of 96 patient-years. These results confirm the benefit of $\mathrm{HU}$, even in very young children, and its possible role in primary stroke prevention. (Blood. 2005; 105:2685-2690)

두 2005 by The American Society of Hematology

\section{Introduction}

Since the first results of the Multicenter Study of Hydroxyurea (MSH) in adult sickle cell anemia patients published by Charache et al, ${ }^{1}$ hydroxyurea (HU) has been successfully used in patients with sickle cell disease (SCD) who have recurrent painful crisis and/or acute chest syndrome (ACS) $)^{2,3}$ as well as in patients with beta-thalassemia major. ${ }^{4}$ In addition to its myelosuppressive effect and ability to induce fetal hemoglobin ( $\mathrm{HbF}$ ) synthesis, HU has been shown to reduce the adhesion of sickle erythrocytes to endothelial cells and to modulate endothelial cell activation and nitric oxide generation. ${ }^{5}$

Whereas HU clinical benefits in severely affected adult SCD patients were confirmed by a randomized controlled trial in 1995 (MSH), ${ }^{1,6}$ its role in very young children requires further studies. , $^{2,10}$

Unanswered questions remain about its sustained efficacy and long-term safety, especially in children who might be exposed to $\mathrm{HU}$ for decades. Since our publication in 2001, ${ }^{2}$ inclusion of patients in the Belgian Registry of SCD patients treated by HU has been ongoing. It has allowed a reassessment of the efficacy and safety of HU, especially in pediatric patients, and the evaluation of its possible role in the prevention of primary stroke or stroke recurrence.

From the Departments of Hematology/Oncology and Radiology, Hôpital Universitaire des Enfants, Brussels, Belgium; the Department of Hematology, Hôpital Universitaire Brugmann, Brussels, Belgium; the Department of Clinical Chemistry, Hôpital Universitaire Erasme, Brussels, Belgium; the Department of Pediatric Hematology, Cliniques Universitaire Saint-Luc, Brussels, Belgium; Clinique de l'Espérance, Montegnée, Belgium; Hôpital de la Citadelle, Liège, Belgium; UZ Gent, Gent, Belgium; Paolakinderziekenhuis, Antwerpen, Belgium; and UZ Gasthuisberg, Leuven, Belgium.

Submitted July 16, 2004; accepted December 3, 2004. Prepublished online as Blood First Edition Paper, December 16, 2004; DOI 10.1182/blood-2004-07-2704.

\section{Patients, materials, and methods}

\section{Patients enrolled}

The Belgian Registry including SCD patients treated by HU was opened in 1993. Approval was obtained from the Pediatric Department of the Children University Hospital Reine Fabiola review board for this registry. Informed consent was provided according to the Declaration of Helsinki. Entry criteria in this registry, clinical monitoring, and laboratory measurements have been described in detail previously. ${ }^{2}$ Briefly, to be eligible, patients had to have reported the year before entry at least 2 or more painful vaso-occlusive crises (VOCs) per year requiring hospitalization; one episode of acute chest syndrome (ACS), defined as acute chest pain with new lung infiltration and $\mathrm{PaO}_{2}$ less than $75 \mathrm{mmHg}$; overt stroke or transient ischemic attack (TIA), defined as transient neurologic deficit (or seizures) and confirmed by a neurologist after electroencephalography and imaging; priapism, defined as persistent painful erection not associated with erotic stimulation; or the development of ischemic bone necrosis, defined as hip or shoulder pain with functional impairment and abnormal bone scintigraphy, magnetic resonance imaging, or radiography.

In one center, routine transcranial Doppler studies (TCDs) were proposed in all patients and performed according to the technique described in the Stroke Prevention Trial (STOP) study. ${ }^{11,12}$ Velocities higher than 200 $\mathrm{cm} / \mathrm{s}$ were considered abnormal. Magnetic resonance imaging (MRI) and angiography (MRA) were performed in the case of abnormal TCD result or 7.4561.01, and 7.4515.03.

Reprints: Alina Ferster, Hemato-Oncology Unit, Hôpital Universitaire des Enfants, Av. J. J. Crocq, 15, B-1020 Brussels, Belgium; e-mail: aferster@ulb.ac.be.

The publication costs of this article were defrayed in part by page charge payment. Therefore, and solely to indicate this fact, this article is hereby marked "advertisement" in accordance with 18 U.S.C. section 1734.

(C) 2005 by The American Society of Hematology 
if judged appropriate by the clinician. Patients only at risk of stroke with at least 2 consecutive transcranial Doppler studies (TCDs) demonstrating a blood-flow velocity of $200 \mathrm{~cm} / \mathrm{s}$ or higher in the median cerebral arteries were also enrolled.

\section{Hydroxyurea therapy}

The HU dose was given orally once a day, initially at $20 \mathrm{mg} / \mathrm{kg}$. It was escalated by $5 \mathrm{mg} / \mathrm{kg}$ if judged appropriate by the treating physician and tolerated by the patient. This was not a centralized treatment protocol: dose escalation, as well as the attempt to reach the maximum tolerated dose (MTD) was not defined by guidelines. Noncompliance with HU therapy could not be assessed by pharmacologic data or by drug dispensing data. Parents, legal guardians, and/or patients were informed of the potential risks, benefits, and side effects relative to HU. Sexually active adolescents were aware of the need of efficient contraception.

\section{Annual data collection}

Initial and annual clinical monitoring evaluation included status of the patient (dead or alive), the number of hospitalizations and duration per year, major SCD-related events, number of transfusions, presence of myelotoxicity, presence of an opportunistic infection, development of a malignant disease, or any other serious adverse event. Baseline and annual laboratory investigations included total hemoglobin level, fetal hemoglobin $(\mathrm{HbF})$, the mean corpuscular volume (MCV), and absolute neutrophil count (ANC). Values within 3 months after a blood transfusion were excluded. The hematologic toxicity was reported in case of white blood cell (WBC) count less than $3 \times 10^{9} / \mathrm{L}$ and platelet count less than $100000 \times 10^{9} / \mathrm{L}$. The mean $\mathrm{HU}$ dose per kilo was calculated each year.

\section{Statistical methods}

Statistical analyses were performed using the Wilcoxon signed rank test to assess significant differences between clinical events or hematologic parameters, before and during $\mathrm{HU}$ treatment.

\section{Results}

\section{Patient characteristics, treatment, and compliance}

Between 1993 and 2002, 127 patients were enrolled in the Belgian Registry: 109 for conventional criteria (99 for 2 or more VOCs, 21 for an acute chest syndrome, 7 for stroke, and 1 for transient ischemic attack) and 18 for abnormal TCD only. Of the patients, 119 had a diagnosis of $\mathrm{HbSS}, 4$ of $\mathrm{HbS}^{\circ}$-thalassemia, 3 of $\mathrm{HbSC}$, and 1 of $\mathrm{HbSD}$. The $\alpha$-globin genotype was unknown for most of the patients. Median age at entry was 6 years (range, 8 months to 19 years), and mean follow-up was 47 months (range, 1-8 years).

Daily hydroxyurea doses reported each year are shown in Table 1. Of the 109 patients included for severe clinical events, $2(1.8 \%)$ received hydroxyurea doses higher than $30 \mathrm{mg} / \mathrm{kg}$ per day (Table 1). The 18 patients enrolled for an abnormal TCD received similar doses, and none of them had hydroxyurea doses higher than 30 $\mathrm{mg} / \mathrm{kg}$ per day.

HU was interrupted definitely for 12 patients: 7 underwent allogeneic bone marrow transplantation, 1 failed to respond after 2 years of treatment, 1 with $\mathrm{HbSC}$ because of a total $\mathrm{Hb}$ level higher than $13 \mathrm{~g} / \mathrm{dL}, 2$ refused to pursue the treatment after 1 and 2 years, and 1 patient developed malignancy. Hydroxyurea was also transiently stopped in 3 cases, 2 for pregnancy and 1 for systemic lupus syndrome, diagnosed one year after the beginning of treatment. Due to relocation, 11 patients were lost to follow-up in the registry.

In some adolescents, poor compliance was evident. Nevertheless, they were encouraged to continue the follow-up in the registry, with the exception of those who refused explicitly.

\section{Adverse event}

The mean number of hospitalizations and duration dropped significantly during the 8 years of HU treatment $(P<.05$ when compared with baseline values, Table 1). Of patients meeting clinical event inclusion criteria, 92 (87\%) of 106 were free of major events requiring hospitalization at 1 year, while at 7 and 8 years after initiation of treatment, $6(25 \%)$ of 24 and $5(36 \%)$ of 14 patients, respectively, remained so. For these 109 patients included for standard criteria, sickle cell-related event rates are presented in Table 2. This represents 426 patient-years of follow-up.

Despite a sustained increase in $\mathrm{HbF}$ level and an increase in hydroxyurea doses to $30 \mathrm{mg} / \mathrm{kg}$ per day, a girl aged 13 months at inclusion, with previous history of splenic sequestration, was hospitalized 20 times during these 2 years of HU therapy and continued to present multiple vaso-occlusive crises and dactylitis during the first year of HU. She died during the second year of therapy from acute severe anemia during an episode of splenic sequestration. Acute promyelocytic leukemia was diagnosed in a 21-year-old female after 8 years of HU therapy. This patient has been treated with all trans-retinoic acid and polychemotherapy and has now been in remission for 20 months. In 6 cases, transient hematologic toxicity was reported. There were 2 patients who

Table 1. Clinical outcome in SCD patients included for standard criteria before and during therapy

\begin{tabular}{|c|c|c|c|c|c|c|c|c|c|}
\hline & \multicolumn{9}{|c|}{ Duration of hydroxyurea therapy } \\
\hline & Before & $1 \mathrm{y}$ & $2 y$ & $3 y$ & $4 y$ & $5 y$ & $6 y$ & $7 y$ & $8 y$ \\
\hline No. of evaluable patients & 109 & 106 & 88 & 70 & 54 & 39 & 32 & 24 & 14 \\
\hline Hospitalizations per patient per year & $3.2 \pm 2.7$ & $1.3 \pm 2.2^{*}$ & $1.6 \pm 2.9^{*}$ & $1.1 \pm 1.5^{\star}$ & $1.3 \pm 1.9^{*}$ & $1.3 \pm 1.5^{\star}$ & $1.6 \pm 1.7 \dagger$ & $1.0 \pm 1.3^{*}$ & $0.6 \pm 1.2 \dagger$ \\
\hline Days in hospital per patient per year & $20 \pm 17$ & $6.8 \pm 14^{*}$ & $7.1 \pm 12^{*}$ & $5.7 \pm 8.5^{\star}$ & $7.9 \pm 11 \dagger$ & $7.7 \pm 9.6 \dagger$ & $10 \pm 13 \dagger$ & $6.7 \pm 8.3 \dagger$ & $3.7 \pm 7.0 \dagger$ \\
\hline \multicolumn{10}{|l|}{$\begin{array}{l}\text { Mean hydroxyurea dose, } \mathrm{mg} / \mathrm{kg} \text { daily, } \\
\text { no.‡ }\end{array}$} \\
\hline Less than 20 & NA & 52 & 47 & 40 & 30 & 23 & 19 & 10 & 8 \\
\hline Between 20 to 25 & NA & 49 & 33 & 21 & 18 & 12 & 7 & 11 & 4 \\
\hline Between 25 to 30 & NA & 2 & 8 & 7 & 4 & 3 & 5 & 2 & 1 \\
\hline More than 30 & NA & 1 & 1 & 1 & 2 & 1 & 1 & 1 & 0 \\
\hline
\end{tabular}

Results are mean $\pm 1 \mathrm{SD}$.

*Statistically significant change from baseline, defined by $P<.001$.

†Statistically significant change from baseline, defined by $P<.05$.

fData missing for 4 patient-years.

NA indicates not applicable. 
Table 2. Cumulative event numbers and rates during an 8-year follow-up for 109 patients enrolled for standard criteria during 426 patient-years

\begin{tabular}{lcc}
\hline \multicolumn{1}{c}{ Type of event } & $\begin{array}{c}\text { Adverse } \\
\text { events, } \mathbf{n}\end{array}$ & $\begin{array}{c}\text { Rate/100 } \\
\text { patient-years }\end{array}$ \\
\hline Hospitalizations, no. & 587 & 138 \\
Hospitalization, d & 4400 & 1033 \\
Vaso-occlusive crisis requiring hospitalization, & 93 & 22 \\
$\quad$ 2 or more than 2/y & 14 & 3.3 \\
Acute chest syndrome & $6^{*}$ & 1.3 \\
Cerebrovascular event & 5 & 1.1 \\
Osteonecrosis & 1 & 0.23 \\
Priapism & 0 & 0 \\
Opportunistic infection & 6 & 1.4 \\
Transient hematologic toxicity & 1 & 0.23 \\
Death & 1 & 0.23 \\
Malignancy & & \\
\hline
\end{tabular}

*There was 1 stroke and 5 TIAs. The patient who had stroke on HU had had initial stroke. The 5 TIA occurred in patients without any previous central nervous system (CNS) symptoms.

became pregnant on $\mathrm{HU}$ and gave birth to healthy babies. No opportunistic infection occurred.

\section{Long-term effects of hydroxyurea therapy}

Adverse events and laboratory values of a cohort of 32 patients (15 females and 17 males) maintained over 6 years on HU were analyzed (Tables 3-4). All of them were diagnosed as homozygous for $\mathrm{HbS}$. Median age at entry was 6 years (range, 8 months to 19 years). Hospitalizations, VOCs, and ACS were more frequently observed after 3 years of treatment than during the first 3 years. Recurrent stroke was observed once in an 8-year-old girl, 6 years after the initial event. No strokes or TIAs occurred in the 31 patients without a history of previous stroke or TIA. During the 6 years of HU therapy, $8(25 \%)$ of 32 patients remained free from any sickle cell disease-related event requiring hospitalization. With time, a larger proportion of patients received an HU dose of less than $20 \mathrm{mg} / \mathrm{kg}$ per day: 36 (38\%) of 96 during the years 1 to 3 and $52(54 \%)$ of 96 during the fourth to sixth years. Nevertheless, hematologic response to $\mathrm{HU}$ was sustained, and no significant difference could be observed between the hematologic values in the third year and those obtained at years 4,5 , and 6 .

\section{Risk of cerebrovascular events}

There were 8 patients followed for a median of 6 years (range, 3-9 years), with 44 cumulative patient-years of follow-up, at risk of secondary stroke. Median age at entry was 7 years (range, 8 months to 19 years), and one patient received hydroxyurea doses higher than $30 \mathrm{mg} / \mathrm{kg}$ per day. At entry, 3 patients were no longer transfused because of poor compliance, parents' refusal, or alloimmunization, while 5 patients were still under a chronic transfusion program for $3(\mathrm{n}=2)$ and $4(\mathrm{n}=3)$ months. Recurrent stroke occurred in one patient after 6 years of follow-up despite evidence of good compliance with therapy as assessed by hematologic response to $\mathrm{HU}$.

Among the 101 patients included for standard criteria and no previous stroke or TIA, 54 were evaluated by TCD before and/or during $\mathrm{HU}$ treatment. Of the patients, 16 presented with velocities more than $200 \mathrm{~cm} / \mathrm{sec}$ (mean, $229 \pm 13 \mathrm{~cm} / \mathrm{sec}$ ). In 11 of 16 who had measurements performed before the start of $\mathrm{HU}$, similar values were obtained $(230 \pm 14 \mathrm{~cm} / \mathrm{sec})$. MRI/MRA was performed in 12 and considered abnormal in 4 patients.
Among the 18 patients included in the registry on the basis of an abnormal TCD alone, baseline TCD velocities were of $228 \pm 19$ $\mathrm{cm} / \mathrm{sec}$. Of the patients, 11 have been prospectively followed by TCD and 2 of them had TCD velocities that returned to normal/ conditional value on HU. The mean TCD velocities in this group of 11 patients decreased from $235 \pm 25 \mathrm{~cm} / \mathrm{sec}$ to $204 \pm 27 \mathrm{~cm} / \mathrm{sec}$ $(P<.01)$. Among these 18 patients, 14 underwent MRI/MRA studies, which were interpreted as abnormal in 3 patients. In this group of 18 patients, the median age at entry was 5 years (range, 1-17 years), and median duration of follow-up was 3 years (range, 1-6 years). Mean daily doses of $\mathrm{HU}$ as well as hematologic response to $\mathrm{HU}$ were similar to that of the whole cohort (data not shown).

As a whole, 34 patients were considered at risk of primary stroke on the basis of abnormal TCD, and 7 of the 21 explored by MRI/MRA had moderate/severe arterial stenosis. Only 1 of these 34 patients presented a cerebrovascular event (seizures) after an evaluation of 96 patient-years. Neuropsychologic evaluation was not performed in this cohort.

\section{Follow-up of patients younger than 2 years}

Included in the registry were 14 patients younger than 2 years, and 10 of them had a minimum follow-up of 2 years of HU therapy. Their clinical events and hematologic values during therapy were compared with those observed in older patients with the same follow-up of 2 years and aged of 2 to 5,6 to 9 , and 10 to 19 years (Tables 5-6). Reduction of hospitalizations and VOCs on HU was significant in all 4 age groups, when compared with baseline data. The rate of sickle cell-related events as well as the number of hospitalizations on HU were similar in all age groups, but the hospitalization durations were longer in the younger group. One patient who died was described previously. The 10 infants initially received a dose of less than $20 \mathrm{mg} / \mathrm{kg}$ per day, which was increased

Table 3. Cumulative event numbers and rates during a 6-year follow-up of 32 patients

\begin{tabular}{|c|c|c|}
\hline \multirow[b]{2}{*}{ Type of event } & \multicolumn{2}{|c|}{ Years of HU therapy } \\
\hline & 1 to 3 & 4 to 6 \\
\hline \multicolumn{3}{|l|}{ Hospitalizations, no. } \\
\hline No. & 82 & 142 \\
\hline Rate/100 patients-years & 85 & 148 \\
\hline \multicolumn{3}{|l|}{ Hospitalizations, d } \\
\hline No. & 446 & 855 \\
\hline Rate/100 patients-years & 465 & 890 \\
\hline \multicolumn{3}{|c|}{ Vaso-occlusive crisis, 2 or more than $2 / y$} \\
\hline No. & 15 & 22 \\
\hline Rate/100 patients-years & 16 & 23 \\
\hline \multicolumn{3}{|l|}{ Acute chest syndrome } \\
\hline No. & 0 & 3 \\
\hline Rate/100 patients-years & 0 & 3.1 \\
\hline \multicolumn{3}{|l|}{ Cerebrovascular event } \\
\hline No. & 0 & 1 \\
\hline Rate/100 patients-years & 0 & 1 \\
\hline \multicolumn{3}{|l|}{ Bone necrosis/dactylitis } \\
\hline No. & 1 & 0 \\
\hline Rate/100 patients-years & 1 & 0 \\
\hline \multicolumn{3}{|l|}{ Severe anemia } \\
\hline No. & 3 & 3 \\
\hline Rate/100 patients-years & 3.1 & 3.1 \\
\hline \multicolumn{3}{|c|}{ Mean hydroxyurea dose, mg/kg daily, no. } \\
\hline Less than 20 & 36 & 52 \\
\hline Between 20 to 25 & 47 & 26 \\
\hline More than 25 & 13 & 20 \\
\hline
\end{tabular}


From www.bloodjournal.org by guest on May 22, 2016. For personal use only.

Table 4. Biologic outcome during a 6 -year follow-up of 32 patients

\begin{tabular}{|c|c|c|c|c|c|c|c|}
\hline & \multicolumn{7}{|c|}{ Hydroxyurea therapy } \\
\hline & Before & 1 year & 2 years & 3 years & 4 years & 5 years & 6 years \\
\hline Hemoglobin level, g/dL & $8.2(6.7-10)$ & $8.7(6.7-12) \dagger$ & $9.0(6.2-12)^{\star}$ & $8.7(6.8-13) \dagger$ & $8.6(6.6-14) \dagger$ & $8.8(6.7-14) \dagger$ & $8.8(6.9-11) \dagger$ \\
\hline HbF level, g/dL & $0.3(0.01-0.8)$ & $1.4(0.01-5.1)^{\star}$ & $1.4(0.12-4.3)^{\star}$ & $1.4(0.17-3.8)^{\star}$ & $1.3(0.16-3.2)^{\star}$ & $1.0(0.10-2.8)^{\star}$ & $1.1(0.08-2.5)^{\star}$ \\
\hline MCV, fL & $83(68-113)$ & $93(69-117)^{\star}$ & $93(75-118)^{*}$ & $91(70-118)$ & $93(74-119)$ & $91(70-121)$ & $92(67-120)$ \\
\hline ANC, $\times 10^{9} / \mathrm{L}$ & $5.2(2.8-9.3)$ & $3.4(1.4-6.6)^{\star}$ & $4.5(1.3-12)$ & $4.2(2.2-11)$ & $4.3(0.8-10)$ & $4.8(1.5-11)$ & $4.6(2.0-15)$ \\
\hline
\end{tabular}

No statistically significant change at 4,5 , and 6 years respectively for all parameters when compared with 3 years.

Results are expressed as median (range).

* Statistically significant change from baseline, defined by $P<.001$.

†Statistically significant change from baseline, defined by $P<.05$.

for 2 of them. The infant who died was treated with $30 \mathrm{mg} / \mathrm{kg}$ per day of HU but without significant leuco- or thrombocytopenia.

Toxicities of HU were reported with 2 transient episodes of thrombocytopenia ( 2 infants) that required temporary discontinuation of therapy. There were 5 episodes observed of severe anemia $(\mathrm{Hb},<6 \mathrm{~g} / \mathrm{dL}$ ) that required transfusion (4 infants). Aplastic crisis associated with a Parvovirus infection was documented in one patient.

\section{Discussion}

The ongoing experience with the prospective Belgian Registry for severe sickle cell disease patients treated with HU confirms our previous results ${ }^{2}$ that long-term HU therapy is feasible and is associated with a clinical improvement (reduction of hospitalization numbers and duration). As found in our previous study, ${ }^{2}$ the majority of patients no longer experienced VOCs requiring hospitalization during the first year of HU treatment. In the cohort of 32

Table 5. Cumulative event numbers and rates during a 2-year patient follow-up of 4 age groups

\begin{tabular}{|c|c|c|c|c|}
\hline \multirow[b]{2}{*}{ Type of event } & \multicolumn{4}{|c|}{ Age at inclusion, $y$} \\
\hline & $\begin{array}{c}\text { Younger than } \\
2(n=10)\end{array}$ & $\begin{array}{c}2 \text { to } 5 \\
(n=28)\end{array}$ & $\begin{array}{c}6 \text { to } 9 \\
(n=28)\end{array}$ & $\begin{array}{l}10 \text { to } 19 \\
(n=26)\end{array}$ \\
\hline \multicolumn{5}{|l|}{ Hospitalizations, no. } \\
\hline No. & 32 & 63 & 113 & 47 \\
\hline Rate/100 patients-years & 160 & 112 & 226 & 90 \\
\hline \multicolumn{5}{|l|}{ Hospitalizations, d } \\
\hline No. & $224^{\star}$ & 296 & 406 & 261 \\
\hline Rate/100 patients-years & 1120 & 529 & 812 & 502 \\
\hline \multicolumn{5}{|l|}{$\begin{array}{c}\text { Vaso-occlusive crisis, } 2 \\
\text { or more than } 2 / y\end{array}$} \\
\hline No. & 2 & 10 & 9 & 10 \\
\hline Rate/100 patients-years & 10 & 18 & 18 & 19 \\
\hline \multicolumn{5}{|l|}{ Acute chest syndrome } \\
\hline No. & 0 & 1 & 2 & 0 \\
\hline Rate/100 patients-years & 0 & 1.8 & 4 & 0 \\
\hline \multicolumn{5}{|l|}{ Cerebrovascular event } \\
\hline No. & 1 & 0 & 0 & 0 \\
\hline Rate/100 patients-years & 5 & 0 & 0 & 0 \\
\hline \multicolumn{5}{|l|}{ Bone necrosis/dactylitis } \\
\hline No. & 1 & 0 & 0 & 1 \\
\hline Rate/100 patients-years & 5 & 0 & 0 & 1.9 \\
\hline \multicolumn{5}{|l|}{ Death } \\
\hline No. & 1 & 0 & 0 & 0 \\
\hline Rate/100 patients-years & 5 & 0 & 0 & 0 \\
\hline \multicolumn{5}{|l|}{ Severe anemia } \\
\hline No. & 5 & 2 & 0 & 0 \\
\hline Rate/100 patients-years & 25 & 3.6 & 0 & 0 \\
\hline
\end{tabular}

${ }^{*}$ One child with recurrent splenic sequestrations accounted for 156 days. patients treated for 6 years, clinical improvement persisted throughout this period with significant reduction of the number of hospitalizations and duration compared with baseline data. Nevertheless, more events were reported during years 4 to 6 than 1 to 3 , possibly due to observed reduced treatment intensity during the latter period. This reduced treatment intensity could be explained by the absence of strict guidelines for HU dose modification and by the tailoring of therapy by the treating physician based on the biologic response of each patient. Biologic improvement was maintained throughout the period of therapy, except for the ANC, which diminished, but not significantly, during years 4 to 6 . Recently, Zimmerman et $\mathrm{al}^{13}$ have shown that additional changes are obtained when HU is used at MTD. In their pediatric cohort at the Duke Medical Center, a significant increase in $\mathrm{Hb}, \mathrm{HbF}$, and MCV was obtained when compared with the Belgian cohort without a significant increase in toxicity. The Belgian and the Duke patients are similar in terms of number, mean treatment duration, and follow-up. Nevertheless, in the Belgian cohort, patients were younger (median age, 6 years compared with 11 years in the Duke series) and HU was used at lower doses: of the 426 evaluable patient-years, 229 received less than $20 \mathrm{mg} / \mathrm{kg}$ per day and only 7 (1.6\%), more than $30 \mathrm{mg} / \mathrm{kg}$ per day, while in the Duke series 21 patients $(17 \%)$ received more than $30 \mathrm{mg} / \mathrm{kg}$ per day. The additional clinical benefit of HU used at MTD in terms of VOC rate remains to be proved in children.

Regarding specific events while on HU, the incidence of ACS on $\mathrm{HU}$ is 3.3 episodes for 100 patient-years, whereas the expected incidence of ACS in a pediatric cohort of untreated patients is 25.3 episodes per 100 patient-years in children of 2 to 4 years of age, and this decreases gradually with age to reach an incidence of 9.3 in children of 10 to 19 years. ${ }^{14}$ This lower-than-expected incidence of ACS with HU treatment confirms our previous data. In the MSH study, ${ }^{1} 299$ adults were randomized to receive HU or placebo for a period of approximately 2 years. During the trial period, 75 ACS events occurred and were 2 times more frequent in the placebo arm (51 events) than in the HU arm (25 events). While the MSH study aimed to escalate the dose up to the highest possible dose without myelosuppression, our data confirm that HU is efficient at preventing ACS without reaching the maximum tolerated dose.

The overall incidence of cerebrovascular accident (CVA) in our population is notably higher (1.3 for 100 patient-years) than described in a large cohort of more than 3000 children by Ohene-Frempong et al, ${ }^{15}$ who reported a prevalence of $4 \%$ and an incidence of 0.61 per 100 patient-years. This discrepancy of observations may be related to the population of the Belgian Registry, which is composed of severely affected patients and does not represent a population of unselected SCD patients. More interesting are the data on patients at risk of secondary stroke. Recurrence rate of CVA in our patients with stroke or TIA (1/8) is 
From www.bloodjournal.org by guest on May 22, 2016. For personal use only.

Table 6. Biologic outcome in 4 patient age groups during treatment with $\mathrm{HU}$

\begin{tabular}{|c|c|c|c|c|}
\hline & \multicolumn{4}{|c|}{ Group age at inclusion, $y(n)$} \\
\hline & Younger than $2(10)$ & 2 to $5(28)$ & 6 to $9(25)$ & 10 to $19(26)$ \\
\hline \multicolumn{5}{|l|}{ At inclusion } \\
\hline Hemoglobin level, g/dL & $8.2(6.5-12)$ & $8.1(6.3-10)$ & $7.9(6.4-10)$ & $8.7(7.0-10)$ \\
\hline HbF leve, g/dL & $0.66(0.52-2.4)$ & $0.59(0.15-2.2)$ & $0.46(0.03-2.8)$ & $0.41(0.15-2.5)$ \\
\hline$M C V, f L$ & $79(73-93)$ & $82(68-113)$ & $85(67-95)$ & $88(70-101)$ \\
\hline ANC, $\times 10^{9} / \mathrm{L}$ & $6.5(2.4-8.4)$ & $5.6(2.4-12)$ & $5.7(2.7-17)$ & $5.7(2.8-11)$ \\
\hline \multicolumn{5}{|l|}{ Second-year HU } \\
\hline Hemoglobin level, g/dL & $7.6(2.3-10)$ & $8.9+(6.2-12)$ & $8.6+(6.5-12)$ & $8.9(7.1-12)$ \\
\hline $\mathrm{HbF}$ leve, g/dL & $1.6^{*}(0.35-2.4)$ & $1.5 \dagger(0.24-4.3)$ & $1.3^{*}(0.12-4.5)$ & $1.3^{*}(0.15-3.8)$ \\
\hline$M C V, f L$ & $94^{*}(74-109)$ & $91^{\star}(81-102)$ & $92^{\star}(80-117)$ & $96^{*}(70-110)$ \\
\hline ANC, $\times 10^{9} / \mathrm{L}$ & $4.2(1.4-7.3)$ & $5.0(2.5-10)$ & $4.1^{*}(1.3-12)$ & $3.9^{*}(1.3-9.5)$ \\
\hline
\end{tabular}

Results are expressed as median (range).

*Statistically significant change from baseline, defined by $P<.001$.

†Statistically significant change from baseline, defined by $P<.05$.

low compared with the $50 \%$ expected rate of recurrence of CVA in untransfused patients. ${ }^{15,16}$ In transfused patients, the prevalence of recurrent stroke has been reported at $13 \%$ to $22 \%$ (with one recurrence for each 24-41 patient-years) and the prevalence of TIA is $19 \% .{ }^{16,17} \mathrm{~A}$ similar recurrence rate on $\mathrm{HU}$ was observed in our 8 untransfused patients with 44 patient-years of follow-up. Ware et $\mathrm{al}^{3}$ have reported a cohort of 16 children with previous stroke or TIA in whom chronic transfusion was stopped and replaced by HU. After a median follow-up of 22 months, 3 patients had recurrence of stroke, but recurrences happened shortly after cessation of transfusion, when the increase of $\mathrm{HbF}$ was not optimal. These preliminary data have been confirmed in a cohort of 35 children on HU for a median time of 42 months: the stroke recurrence rate was 5.7 per 100 patient-years but 3.6 per 100 patient-years in children who continued transfusions for a few months. ${ }^{18}$ In 5 of our patients, chronic transfusion has been continued for at least 3 months after the start of $\mathrm{HU}$, and this might explain why they did not experience early recurrence. In another cohort of 5 patients, ${ }^{19} \mathrm{HU}$ was effective at preventing recurrent stroke. Our results, as well as those described by Ware et $\mathrm{al}^{18}$ and Sumoza et al, ${ }^{19}$ suggest that chronic transfusion might be safely stopped after the start of $\mathrm{HU}$ therapy and that HU may prevent stroke recurrence when chronic transfusion is not possible.

Several prospective series have shown that elevated blood flow velocities measured by TCD predict stroke, ${ }^{11,12}$ and when velocities are higher than $200 \mathrm{~cm} / \mathrm{s}$, the risk is above $10 \%$ to $13 \%$ per year. The randomized STOP study ${ }^{20}$ clearly demonstrated that stroke was prevented by chronic transfusions, as one event occurred in the transfusion group, whereas 11 occurred in the standard care group, after a median follow-up of 22 months, leading to early closure of the study. Nevertheless, adherence to a prophylactic chronic transfusion program by patients, parents, and doctors is low, due to risks, costs, and side effects. In particular, the Belgian experience with chronic transfusion is very disappointing because of a high rate of severe alloimmunization, mainly explained by the absence of blood donors of African origin. The limited experience in the 34 patients at risk of primary stroke (18 without any other classical severity criteria and 16 with standard criteria) and treated with $\mathrm{HU}$ is very encouraging. It suggests that $\mathrm{HU}$ might be an alternative to a chronic transfusion program in this subset of patients, since only one event (seizures) occurred with an experience of 96 patientyears. More interestingly, these patients are comparable with those of the STOP study, with similar baseline TCD velocities and almost the same proportion of moderate/severe stenosis on MRA (7/26 versus 25/100 in STOP study). ${ }^{21}$ Slight total hemoglobin increase, inversely correlated to cerebral blood flow velocity, the significant lowering of ANC, as well as reduced neutrophil activation ${ }^{22}$ and adherence molecules expression with $\mathrm{HU}^{23}$ might have contributed to the stabilization of the pathologic process at this level. In our small series, TCD velocities were improved in a group of 11 patients prospectively followed but returned to normal/conditional value in only 2, while in the STOP study improvement/ normalization of blood flow velocities was achieved mostly after transfusions in 26 of 38 patients without severe MRA abnormalities. $^{21}$ The possible equivalence between HU and a conventional transfusion program for primary and secondary stroke prevention should be assessed by a prospective randomized study. Furthermore, we question if, for optimal stroke prevention, the use of MTD would not be beneficial since in the Duke experience no new cerebrovascular event occurred in a similar cohort of patients. ${ }^{13}$ The use of HU instead of transfusion for stroke prevention will avoid the risk of iron overload and the need of iron chelation. ${ }^{18}$ It will also reduce the development of multiple red cell alloantibodies and the risk of viral transmission in areas where the use of blood is not safe.

The overall HU tolerance was good with neither prolonged myelosuppression nor opportunistic infections. The extremely low rate of reported hematologic toxicity might be due to methodologic bias (registry with annual report and not a prospective trial). Nevertheless, this also may be explained by the nonattempt to reach MTD with the majority of patients receiving a dose of less than $20 \mathrm{mg} / \mathrm{kg}$ per day. Furthermore, the definition of myelotoxicity differs slightly from the Duke series, and adolescents with poor compliance were not excluded from the analysis. Long-term treatment was not associated with increased toxicity, while reduction in ANC and elevation in total $\mathrm{Hb}$ and $\mathrm{HbF}$ remained stable throughout the years, suggesting that marrow exhaustion does not occur after such a follow-up.

The development of acute promyelocytic leukemia in one 21-year-old woman after receiving HU for 8 years $^{24}$ is of concern and raised the question of possible SCD or HU-related malignancies. Patients with long-term exposure to HU showed no increase of number of acquired DNA mutations. ${ }^{25}$ Increase of illegitimate variable-diversity-joining region (VDJ) recombination in children on HU has previously been suspected. ${ }^{25}$ However, in the prospective follow-up of the Duke series, no significant increase of illegitimate VDJ recombination after 5 years on $\mathrm{HU}$ was found. ${ }^{13}$ This suggests that long-term continuous follow-up and prospective registration of patients is the only way to evaluate the risk and should be mandatory.

Repeated vaso-occlusive crises are sometimes present from infancy and early childhood. Furthermore, dactylitis, anemia, and 
high WBC counts in infancy predict a severe outcome, and this could trigger an early start of $\mathrm{HU}$ in these patients. ${ }^{7,26} \mathrm{We}$ wondered if the biologic and clinical responses to $\mathrm{HU}$ and toxicity were different in very young children when compared with older ones. Wang et $\mathrm{al}^{7}$ have shown that treatment with $\mathrm{HU}$ is feasible in very young children and might delay functional asplenia. Nevertheless, efficacy among different age groups has never been prospectively studied and compared until now. Followed prospectively for 2 years, 4 age groups of children (younger than 2 years, 2-5 years, 6-9 years and 10-19 years) had similar biologic values at inclusion, except for $\mathrm{HbF}$ that was, as expected, significantly higher in children younger than 2 years. Fetal hemoglobin and MCV values changed similarly with treatment in all age groups, but $\mathrm{Hb}$ levels did not rise significantly in the younger group. Children younger than 2 years had clinical response similar to older patients, except for days in the hospital. Clinically, reduction of the number of hospitalizations and duration each year on $\mathrm{HU}$ was significant in all 4 age groups, when compared with baseline value, and did not differ statistically among the 4 groups, demonstrating that similar improvement is obtained regardless of age. Of interest, 4 of the children included in the registry at younger than 2 years developed episodes of severe acute anemia. Unfortunately, detailed data on each case are not available and information on splenic size or Parvovirus infection was missing for some patients in the database, making further discussion hazardous. However, the patient who died from severe anemia during splenic sequestration is compa- rable with the one described by Wang et al. ${ }^{7}$ In their experience, among 28 enrolled children who were younger than 2 years, only 21 completed 2 years of treatment. One patient died of a fatal episode of splenic sequestration before completing 2 years of treatment. These 2 patients raise the question of HU benefit and safety in very young patients at risk of severe anemia and/or splenic sequestration. At this moment, these 2 deaths should not be interpreted as toxic death, but rather as a lack of efficacy of HU in this specific situation. Our data do not support the use of HU for very young children to limit the severity of anemia, since Hb level did not increase significantly in this group, but the ongoing BABY-HUG trial will answer this question.

The ongoing experience of the Belgian Registry confirms the clinical benefit of treatment with HU, even in very young children. The effectiveness of HU for primary or secondary stroke prevention is possible, and this should continue to be assessed prospectively, ideally by means of randomized trials. The use of $\mathrm{HU}$ at MTD may bring additional benefit. The Belgian Registry continues to provide us with a useful instrument to measure safety and efficacy of HU treatment.

\section{Acknowledgment}

We would like to thank Dr L. Hookey for his substantial editorial assistance.

\section{References}

1. Charache S, Terrin ML, Moore RD, et al. Effect of hydroyurea on the frequency of painful crises in sickle cell anemia: investigators of the Multicenter Study of Hydroxyurea in Sickle Cell Anemia. N Engl J Med. 1995;332:1317-1322.

2. Ferster A, Tahriri P, Vermylen C, et al. Five years of experience with hydroxyurea in children and young adults with sickle cell disease. Blood. 2001;97:3628-3632.

3. Ware RE, Zimmerman SA, Schultz WH. Hydroxyurea as an alternative to blood transfusions for the prevention of recurrent stroke in children with sickle cell disease. Blood. 1999;94:30223026.

4. Bradai M, Abad MT, Pissard S, Lamraoui F, Skopinski L, de Montalembert M. Hydroxyurea can eliminate transfusion requirements in children with severe beta-thalassemia. Blood. 2003;102: 1529-1530.

5. Halsey C, Roberts IAG. The role of hydroyurea in sickle cell disease. Br J Haematol. 2003;120:177186.

6. Steinberg MH, Barton F, Castro O, et al. Effect of hydroxyurea on mortality and morbidity in adult sickle cell anemia: risks and benefits up to 9 years of treatment. JAMA. 2003;289:1645-1651.

7. Wang WC, Wynn LW, Rogers ZR, et al. A twoyear pilot trial of hydroxyurea in very young children with sickle cell anemia. J Pediatr. 2001;139: 790-796.

8. De Montalembert M, Belloy M, Bernaudin F, et al. Three-year follow-up of hydroxyurea treatment in severely ill children with sickle cell disease: The French Study Group on Cell Disease. J Pediatr Hematol Oncol. 1997;19:313-318.

9. De Montalembert M, Begue P, Bernaudin F, Thuret I, Bachir D, Micheau M. Preliminary report of a toxicity study of hydroxyurea in sickle cell disease: French Study Group on Sickle Cell Disease. Arch Dis Child. 1999;81:437-439.

10. Kinney T, Helms R, Branski E, et al. Safety of hydroxyurea in children with sickle cell anemia: results of the HUG-KIDS, a phase I/II trial. Blood. 1999;94:1550-1554.

11. Adams R, Mc Kie V, Nichols F, et al. The use of transcranial ultrasonography to predict stroke in sickle cell disease. N Engl J Med. 1992;326:605610

12. Adams RJ, McKie VC, Carl EM, et al. Long-term stroke risk in children with sickle cell disease sreened with transcranial Doppler. Ann Neurol. 1997;42:699-704.

13. Zimmerman S, Schultz W, Davis J, et al. Sustained long-term hematologic efficacy of hydroxyurea at maximum tolerated dose in children with sickle cell disease. Blood. 2004;103:20392045.

14. Castro O, Brambila DJ, Thorington B, et al. The acute chest syndrome in sickle cell disease: incidence and risk factors: The Cooperative Study of Sickle Cell Disease. Blood. 1994;84:643-649.

15. Ohene-Frempong K, Weiner SJ, Sleeper LA, et al, and the Cooperative Study of Sickle Cell Disease. Cerebrovascular accidents in sickle cell disease: rates end risk factors. Blood. 1998;91: 288-294.

16. Pegelow $\mathrm{CH}$, Adams RJ, McKie V, et al. Risk of recurrent stroke in patients with sickle cell disease treated with erythrocyte transfusions. J Pediatr. 1995;126:896-899.

17. Scothorn DJ, Price C, Schwartz D, et al. Risk of recurrent stroke in children with sickle cell disease receiving blood transfusion therapy for at least five years after initial stroke. J Pediatr. 2002 140:348-354.

18. Ware RE, Zimmerman SA, Sylvestre PB, et al. Prevention of secondary stroke and resolution of transfusional iron overload in children with sickle cell anemia using hydroxyurea and phlebotomy. J Pediatr. 2004;145:346-352.

19. Sumoza A, De Bisotti R, Sumoza D, Fairbanks V. Hydroxyurea (HU) for prevention of recurrent stroke in sickle cell anemia (SCA). Am J Hematol. 2002;71:161-165.

20. Adams RJ, McKie VC, Hsu L, et al. Prevention of a first stroke by transfusions in children with sickle cell anemia and abnormal results on transcranial Doppler ultrasonography. N Engl J Med. 1998;339:5-11.

21. Abboud M, Cure J, Granger S, et al. Magnetic resonance angiography in children with sickle cell disease and abnormal transcranial Doppler ultrasonography findings enrolled in the STOP study. Blood. 2004;103:2822-2826.

22. Benkerrou M, Delarche C, Brahimi L, et al. Hydroxyurea corrects the dysregulated L-selectin expression increased $\mathrm{H}(2) \mathrm{O}(2)$ production of polymorphonuclear neutrophils from patients with sickle cell anemia. Blood. 2002;99:2297-2303.

23. Styles LA, Lubin B, Vichinsky E, et al. Decrease of very late activation antigen-4 and CD36 on reticulocytes in sickle cell patients treated with hydroxyurea. Blood. 1997;89:2554-2559.

24. Ferster A, Sariban E, Meuleman N; Belgian Registry of Sickle Cell Disease patients treated with Hydroxyurea. Malignancies in sickle cell disease patients treated with hydroxyurea. $\mathrm{Br} \mathrm{J}$ Haematol. 2003;123:368-369.

25. Hanft VN, Fruchtman SR, Pickens CV, Rosse WF, Howard TA, Ware RE. Acquired DNA mutations associated with in vivo hydroxyurea exposure. Blood. 2000;95:3589-3593.

26. Hoppe C, Vichinsky E, Quirolo K, Van Warmerdam J, Allen K, Styles L. Use of hydroxyurea in children ages 2 to 5 years with sickle cell disease. J Pediatr Hematol/Oncol. 2000;22:330-334. 


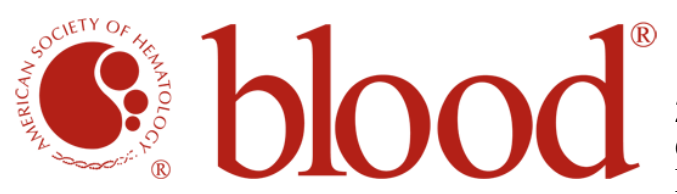

2005 105: $2685-2690$

doi:10.1182/blood-2004-07-2704 originally published online December 16, 2004

\section{Hydroxyurea for sickle cell disease in children and for prevention of cerebrovascular events: the Belgian experience}

Béatrice Gulbis, David Haberman, Dominique Dufour, Catherine Christophe, Christiane Vermylen, Faustin Kagambega, Francis Corazza, Christine Devalck, Marie-Françoise Dresse, Kathleen Hunninck, Axel Klein, Phu Quoc Le, Michèle Loop, Philip Maes, Pierre Philippet, Eric Sariban, Chris Van Geet and Alina Ferster

Updated information and services can be found at:

http://www.bloodjournal.org/content/105/7/2685.full.html

Articles on similar topics can be found in the following Blood collections

Clinical Trials and Observations (4313 articles)

Hemostasis, Thrombosis, and Vascular Biology (2494 articles)

Red Cells (1174 articles)

Information about reproducing this article in parts or in its entirety may be found online at:

http://www.bloodjournal.org/site/misc/rights.xhtml\#repub_requests

Information about ordering reprints may be found online at:

http://www.bloodjournal.org/site/misc/rights.xhtml\#reprints

Information about subscriptions and ASH membership may be found online at:

http://www.bloodjournal.org/site/subscriptions/index.xhtml

Blood (print ISSN 0006-4971, online ISSN 1528-0020), is published weekly by the American Society of Hematology, 2021 L St, NW, Suite 900, Washington DC 20036.

Copyright 2011 by The American Society of Hematology; all rights reserved. 